\title{
Localized Forms of Vasculitis
}

\author{
Joana Martins-Martinho ${ }^{1,2} \cdot$ Eduardo Dourado $^{1,2} \cdot$ Nikita Khmelinskii $^{1,2} \cdot$ Pablo Espinosa $^{3} \cdot$ Cristina Ponte $^{1,3}$
}

Accepted: 21 April 2021 / Published online: 1 July 2021

(C) The Author(s), under exclusive licence to Springer Science+Business Media, LLC, part of Springer Nature 2021

\begin{abstract}
Purpose of Review To provide an updated review on epidemiology, clinical manifestations, diagnostic assessment, treatment, and prognosis of localized vasculitis, following the 2012 Revised International Chapel Hill Consensus Conference Nomenclature on single-organ vasculitis.

Recent Findings Localized, single-organ vasculitides encompass a group of rare conditions in which there is no evidence of concomitant systemic vasculitis. Most data on this topic derives from case reports and small case series. Although some aspects of these diseases, such as clinical manifestations and histologic findings, have already been extensively investigated, there is still a lack of robust data concerning the pathogenesis, epidemiology, and treatment.

Summary Localized vasculitides may have a wide range of clinical features depending on the organ affected. The inflammatory process may have a multifocal/diffuse or unifocal distribution. Diagnosis is usually based on histopathology findings and exclusion of systemic vasculitis, which may frequently pose a challenge. Further research on treatment is warranted.
\end{abstract}

Keywords Single-organ vasculitis $\cdot$ Cutaneous leukocytoclastic angiitis $\cdot$ Cutaneous arteritis $\cdot$ Isolated aortitis

\section{Introduction}

Systemic vasculitides are a group of heterogeneous conditions characterized by inflammation of the blood vessels, commonly affecting various vascular territories and organs. Less frequently,

This article is part of the Topical Collection on Vasculitis

Joana Martins-Martinho

joanamartinsmartinho@gmail.com

Eduardo Dourado

eduardojorgedd@gmail.com

Nikita Khmelinskii

nkhmelinskii@gmail.com

Pablo Espinosa

espinosapab@gmail.com

Cristina Ponte

cristinadbponte@gmail.com

1 Rheumatology Department, Hospital de Santa Maria, Centro Hospitalar Universitário Lisboa Norte, 1649-035 Lisbon, Portugal

2 Rheumatology Research Unit, Instituto de Medicina Molecular, Faculdade de Medicina, Universidade de Lisboa, Lisbon, Portugal

3 Dermatology Department, Hospital de Santa Maria, Centro Hospitalar Universitário Lisboa Norte, 1649-035 Lisbon, Portugal vasculitis may also manifest in a localized fashion, reflecting a limited expression of a systemic vasculitis (e.g., localized granulomatosis with polyangiitis) or a vascular inflammation restricted to only one organ or organ system [1-3]. To facilitate distinction between both forms of localized vasculitis, the 2012 Revised International Chapel Hill Consensus Conference (CHCC) Nomenclature of Vasculitides proposed the term single-organ vasculitis (SOV) to define "vasculitis in arteries or veins of any size in a single organ that has no features that indicate that it is a limited expression of a systemic vasculitis." Currently, it incorporates the following vasculitis: cutaneous leukocytoclastic angiitis, cutaneous arteritis, primary central nervous system (CNS) vasculitis, isolated aortitis, and others [4].

SOV should be named according to the specific organ involved and pattern of inflammation observed. The inflammatory process distribution in SOV may be multifocal/diffuse (e.g., skin, CNS, renal, peripheral nervous system) or unifocal (e.g., aorta, breast, gastrointestinal, and urogenital structures) within an organ or organ system [1-3]. In addition, vascular inflammatory patterns in SOV may be granulomatous or nongranulomatous and, in most cases, are histologically indistinguishable from systemic vasculitis [2].

A few rare cases of patients who are diagnosed initially as having SOV may later evolve into systemic disease (e.g., cutaneous arteritis as the first manifestation of systemic polyarteritis nodosa). Therefore, a minimum disease 
monitoring of 6 months should be guaranteed to confirm the isolated nature of the vasculitis and safely exclude a systemic illness [2].

This review aims to provide the most recent evidence on clinical features and management of the SOV included in the CHCC nomenclature, with a particular focus on leukocytoclastic angiitis and cutaneous polyarteritis nodosa. Other forms of localized, single-organ vasculitis will also briefly be discussed.

\section{Cutaneous Leukocytoclastic Angiitis}

Cutaneous leukocytoclastic angiitis (CLA) has been previously known as cutaneous leukocytoclastic vasculitis, cutaneous small vessel vasculitis, hypersensitivity vasculitis, and cutaneous necrotizing vasculitis. It reflects inflammation of the small-sized blood vessels in the superficial dermis, usually post-capillary venules [5]. CLA differs from cutaneous arteritis in the sense that it affects all small blood vessels (arteries, capillaries, and venules), rather than just the arteries. The term leukocytoclastic refers to the damage caused by nuclear debris from infiltrating neutrophils in and around the vessels, including fibrinoid necrosis [5]. CLA is not a disease entity but represents a vascular reaction pattern mainly due to circulating immune complexes that may include idiopathic and secondary presentations.

CLA is the most common cutaneous vasculitis seen in clinical practice $[5,6]$ with an annual incidence of 45 per million [7]. It occurs in all age groups and has a slight female predominance $[8,9]$. It is much more common in adults than in children [5].

\section{Clinical Features}

CLA is characterized initially by red-to-pink macules and papules, evolving into a fully developed, classic appearance of non-blanching petechiae and palpable purpura (Fig. 1a) [5] . These lesions may coalesce and ulcerate. Urticarial lesions, hemorrhagic bullae, small vesicles, pustules, or erythema multiforme-like lesions may also develop, but are less common [5]. The lesions are most frequently symmetrical and found below the waist, in gravity-dependent areas, or areas of constrictive clothing. In most cases, these lesions do not cause accompanying symptoms; however, itching, burning, or pain may occur [5]. Presence of other CLA-related symptoms will depend on the underlying cause of vasculitis [10].

\section{Association with Systemic Vasculitis and Other Diseases}

In primary CLA, there is no internal organ involvement. However, visceral involvement can occur later in the disease course, revealing a previously occult systemic small vessel vasculitic process. CLA can also have various identifiable causes (Table 1), including medications, infections, such as Corona Virus Disease 2019 (COVID-19) [11, 12], allergens, immune-mediated conditions, and malignancies, most frequently hematologic $[5,10,13 \cdot 14-20]$. Medications and infectious pathogens are most common in adults $[10,13 \cdot$, 14], while $\operatorname{IgA}$ vasculitis frequently affects children [10]. Nevertheless, in around half of the cases, no underlying cause is found $[7,10,13 \cdot 14]$.

In systemic vasculitis, the systemic involvement often precedes the cutaneous lesions, but the interval can be as short as days or as long as years [9]. When the inciting agent is a drug or an infectious agent, most patients develop symptoms from the seventh to the tenth day after antigen exposure [21]. Druginduced antineutrophil cytoplasmic antibody (ANCA)-associated vasculitis (AAV) is a notable exception, in which a year or more can separate the start of the causative medication and the clinical manifestations [8]. There is a large variety of drugs associated with drug-induced ANCA-associated vasculitis which mainly include anti-thyroid drugs and tumor necrosis factor inhibitors [22]. Notably, it has been suggested that the risk of developing AAV may be related to the duration of treatment with some drugs, such as propylthiouracil [22]. When the provoking agent persists, such as in hepatitis $\mathrm{C}$ related cryoglobulinemic vasculitis or rheumatoid arthritis, chronic vasculitis can be observed, with fluctuating lesions or persistent lesions of different ages.

\section{Diagnostic Evaluation}

The assessment of a patient with suspected CLA should be directed at confirming the diagnosis, defining the underlying etiology and excluding major organ involvement. Careful investigation for an inciting factor is imperative because removal of the underlying cause may result in the resolution of the CLA [23]. Patients should be questioned for symptoms suggestive of infection or systemic disease, such as systemic vasculitides or connective tissue diseases. In addition, history of new medication intake, illicit drug consumption, and associated comorbidities should be ascertained.

The request for diagnostic tests should be guided by the patient's history and clinical manifestations. If the CLA cause is not apparent, initial laboratory workup should include a complete blood count, acute phase reactants (erythrocyte sedimentation rate [ESR] and C-reactive protein [CRP]), liver and kidney functions, serum protein electrophoresis, hepatitis $\mathrm{C}$ antibody (and potentially hepatitis B antibodies), and urinalysis with microscopy. Depending on the clinical setting, other laboratory tests may also be appropriate, such as antinuclear antibodies (ANA), complement (CH50, C3, and C4) levels, rheumatoid factor (RF), ANCA, antiphospholipid antibodies, cryoglobulins, and HIV testing. 


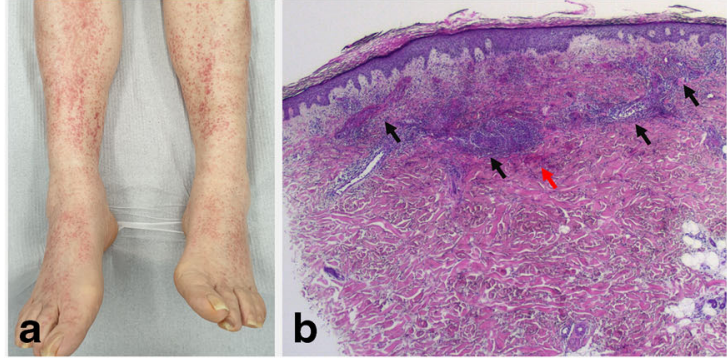

Fig. 1 Cutaneous leukocytoclastic angiitis. (a) Patient with CLA in lower extremities. (b) Inflammation in superficial dermis mostly involving small venules (black arrows), with predominant number of neutrophils and extravasation of erythrocytes (red arrow) $(H \& E \times 25)$. (c) Infiltration
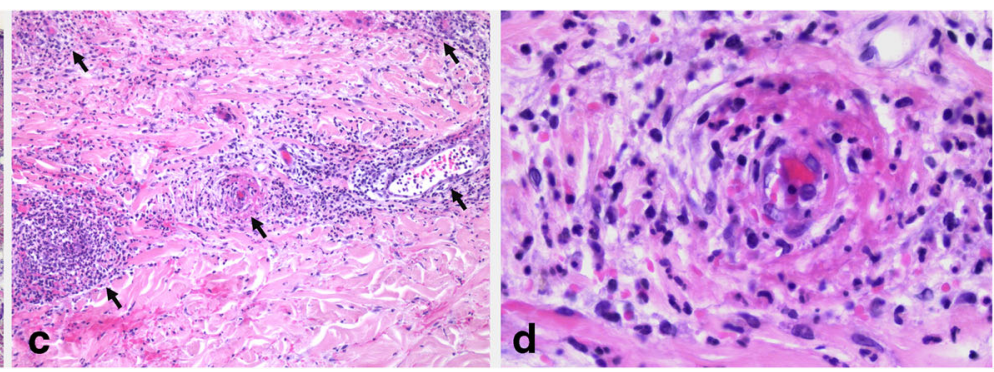

of vessel walls with neutrophils which also extend into de perivascular zone and beyond (black arrows) (H\&E $\times 100$ ). (d) Visible vessel wall damage with necrosis, hyalinization and fibrin, and inflammatory cells in vessel wall $(\mathrm{H} \& \mathrm{E} \times 400)$

In most cases, a skin biopsy should be sought to determine if the clinical findings are truly due to vasculitis [9]. It should preferably be performed within the first $48 \mathrm{~h}$ after the appearance of skin lesions [10]. If more time has passed, the biopsy should be directed at lesions with 24 to $48 \mathrm{~h}$ old $[5,24]$. Typical histologic findings include the presence of vascular and perivascular infiltration, predominantly of neutrophils, particularly affecting the superficial dermal plexus; formation of nuclear dust (leukocytoclasis); extravasated erythrocytes; and fibrinoid necrosis of the vessel walls (Fig. 1b, c, d) [25]. Vasculitis cannot be diagnosed with certainty unless there is visible vessel wall damage and inflammatory cells in vessel walls. Presence of eosinophils may also be seen, pointing towards drug-related CLA. Direct immunofluorescence (DIF) microscopy is an indispensable element of CLA evaluation of unclear cause that persists for more than 4 weeks. It should ideally be performed on a lesion that is less than $24 \mathrm{~h}$ old. In CLA, DIF can show both complement and immunoglobulins in vessel walls; rarely, necrotizing venulitis throughout the mid- and deep-dermis can also be seen [25]. DIF may be crucial to identify the underlying etiology of vasculitis. It is particularly important for the detection of IgA-predominant deposits in IgA vasculitis (Henoch-Schönlein purpura) [26] and for distinguishing immune complex-mediated from the least common pauci-immune vasculitis [27].

\section{Treatment and Prognosis}

Treatment of secondary CLA should be directed towards the underlying cause of the vasculitis. Idiopathic CLA often resolves within a few weeks $[15,16]$, and thus, management of most of these patients includes confirming the lack of an identifiable cause and the alleviation of symptoms [28]. Conservative measures such as leg elevation, stockings, and topical steroids are helpful to relieve the itching and burning sensation [17]. Furthermore, non-steroidal anti-inflammatory drugs (NSAIDs) may be useful for pain management, and oral antihistamines may help to suppress pruritus. Chronic or recurrent disease develops in approximately $10 \%$ of patients $[15,17]$. Presence of cryoglobulins, arthralgia, and absence of fever have been identified as risk factors for chronic cutaneous disease, whereas paresthesia, fever, and absence of painful lesions for systemic involvement [29].

Systemic immunomodulatory therapy is usually reserved for the subset of patients who develop complications [28], such as hemorrhagic bullae, cutaneous necrosis, ulceration, or chronic or recurrent disease. Treatment data for primary CLA is primarily based on case reports [28], so the strength of putative recommendations is very low.

The initial approach to CLA usually includes the use of a short course of prednisone, typically at a dose of $0.5-1 \mathrm{mg} / \mathrm{kg} /$ day until lesion formation stops, followed by a quick taper over 3 to 6 weeks $[28,30]$. Maintenance therapy with colchicine [30, 31] or dapsone [32-34] can be initiated, although there is still limited data supporting their efficacy. Azathioprine (0.5-2.5 $\mathrm{mg} / \mathrm{kg} /$ day) may be used in refractory cases [30,35], with an expected response in the first 2 months of therapy. There is a generalized lack of solid evidence for the use of other immunosuppressants in primary CLA. Methotrexate (10-25 mg/week) has been reported to be effective in CLA secondary to rheumatoid arthritis [36-38], with clinical responses occurring within 4 to 8 weeks. Although hydroxychloroquine is occasionally used in daily practice for treating patients with CLA, there is only scarce evidence for its clinical benefit in urticarial vasculitis $[30,39,40]$. In addition, successful treatment with mycophenolate mofetil ( $2-3 \mathrm{~g} /$ day) has only been documented in a few case reports of refractory primary CLA [41], urticarial vasculitis [42], and IgA vasculitis [43]. For those infrequent cases of severe forms of CLA, rituximab [44-46], infliximab [47], and intravenous immunoglobulin [48] may pose as treatment alternatives. Cyclophosphamide and cyclosporine are usually reserved for refractory, severe, or secondary CLA when other therapies are not available, but with conflicting results [21, 49-51]. Figure 2 shows a proposed treatment algorithm for cutaneous leukocytoclastic angiitis.

When chronic or recurring CLA is asymptomatic, deferring treatment may also be an option. Post-inflammatory hyperpigmentation and red-brown hemosiderin deposits commonly remain in the skin after an episode of CLA. These lesions tend to resolve slowly over time. 
Table 1 Known causes of cutaneous leukocytoclastic angiitis

$\begin{array}{lll}\begin{array}{c}\text { Drugs } \\ \text { Anti-infective } \\ \text { Cephalosporins }\end{array} & \text { Cardiovascular } & \text { Rheumatology } \\ \text { Penicillin } & \text { Furosemide } & \\ \text { Vancomycin } & \text { Spironolactone } & \text { Allopurinol } \\ \text { Erythromycin } & \text { Thiazides } & \text { Colchicine } \\ \text { Doxycycline } & \text { Beta-blockers } & \text { Non-steroidal anti- } \\ \text { Clindamycin } & \text { Amiodarone } & \text { inflammatory drugs } \\ \text { Quinolones } & \text { Diltiazem } & \text { Paracetamol } \\ \text { Trimethoprim- } & \text { Hydralazine } & \text { Cyclophosphamide } \\ \text { sulfamethoxazole } & \text { Captopril } & \text { Methotrexate } \\ \text { Rifampicin } & \text { Warfarin } & \text { Azathioprine } \\ \text { Isoniazid } & \text { Heparin } & \text { TNF inhibitors } \\ \text { Acyclovir } & \text { Metformin } & \text { Secukinumab } \\ \text { Othe } & & \text { Rituximab }\end{array}$

Others

Sulphonamides

Selective serotonin reuptake inhibitors, amitriptyline, trazodone

Tamoxifen

Phenytoin, valproic acid, carbamazepine

Influenza, anti-pneumococcal and BCG vaccines

Radiocontrast media containing iodine

Infection

Post-infectious

Streptococcal upper airway infection

Staphylococcus aureus infections

Chlamydiaceae

Neisseriaceae

Mycobacterial infections

COVID-19

Chronic infections

HIV

Hepatitis B virus

Hepatitis $C$ virus

Syphilis

Endocarditis

Infected shunts

Cancer

$\begin{array}{ll}\text { Blood-borne cancer } & \text { Respiratory tract cancer } \\ \text { Lymphoma } & \text { Lung squamous cell carcinoma } \\ \text { Leukaemia } & \text { Lung adenocarcinoma } \\ \text { Multiple myeloma } & \text { Bronchial carcinoma } \\ \text { Plasmacytoma } & \text { Genito-urinary cancer } \\ \text { Monoclonal gammopathy } & \text { Renal cell carcinoma } \\ \text { Myelofibrosis } & \text { Urinary bladder carcinoma } \\ & \text { Prostate adenocarcinoma }\end{array}$

Gastro-intestinal cancer

Squamous cell carcinoma of oesophagus Intestinal adenocarcinoma

Pancreatic adenocarcinoma

Others

Anaplastic sarcoma

Immune-mediated diseases

Vasculitis
ANCA-associated vasculitis
Cryoglobulinemia
IgA vasculitis
Anti-glomerular basement
membrane disease
Behçet's disease
Hypocomplementemic
urticarial vasculitis

Connective tissue diseases Others

Mixed connective tissue Antiphospholipid syndrome

disease

Systemic lupus Inflammatory bowel disease

erythematosus

Sjögren's syndrome

Erythema elevatum diutinum

$T N F$, Tumor necrosis factor; $B C G$, Bacillus Calmette-Guérin; $H I V$, human immunodeficiency virus; $A N C A$, Anti-neutrophil cytoplasmic antibodies; COVID-19, Corona Virus Disease 2019 
Fig. 2 Proposed treatment algorithm for cutaneous leukocytoclastic angiitis. (1) If refractory primary CLA, urticarial vasculitis, or IgA vasculitis. (2) If CLA secondary to rheumatoid arthritis. (3) If urticarial vasculitis

\section{General measures}

- Determine if there is an identifiable secondary cause

- Leg rest and elevation

- Avoidance of excessive standing or wearing tightfitting clothes

- Stockings

$+$

Topical glucocorticoids

Oral NSAIDs (if pain)

Antihistamines (if pruritus)

If refractory/relapsing:

Add oral prednisone (or equivalent) $(0.5-1 \mathrm{mg} / \mathrm{kg} /$ day) until lesion formation stops (followed by a tapering regimen)

Consider adding colchicine or dapsone for remission maintenance

\begin{tabular}{l} 
If refractory/relapsing: \\
Add azathioprine $(0.5-2.5 \mathrm{mg} / \mathrm{kg} /$ day) \\
Or consider: \\
- Mycophenolate mofetil $^{1}$ \\
- Methotrexate ${ }^{2}$ \\
- Hydroxychloroquine \\
\hline
\end{tabular}

\section{Cutaneous Arteritis}

Cutaneous polyarteritis nodosa (CPAN) was first described by Lindberg in 1931 as a form of polyarteritis nodosa (PAN) limited to the skin [52]. In the 2012 CHCC, CPAN was termed cutaneous arteritis and considered an SOV [4]. Although cutaneous arteritis and systemic PAN are both necrotizing arteritis of the subcutaneous tissue or lower dermis sharing similar cutaneous manifestations, multi-organ involvement only occurs in the latter $[25,53]$.

Cutaneous arteritis is a rare disease, with a currently unknown incidence and prevalence [54]. It can affect all age groups, with an average age of onset between 40 and 50 years $[55,56]$. Cutaneous arteritis is slightly more predominant in women, with a female:male ratio of 1.9-3.4:1 [55-59].

The etiology of cutaneous arteritis remains unclear. A potential association with the deposition of immune complexes has been reported, with previous studies revealing IgM and C3 deposits in the arterial wall by DIF [60, 61]. Moreover, the use of minocycline, history of infections by group $A \beta$ hemolytic Streptococcus, and other conditions such as inflammatory bowel have been associated with cutaneous arteritis
[62-66]. A genetic deficiency of adenosine deaminase type 2 (ADA2) has also been reported as a cause for cutaneous arteritis vasculopathy $[67,68]$.

\section{Clinical Features}

Cutaneous arteritis usually presents with tender nodules in $28.6-100 \%$ of cases, often multiple, with a red-dark or reddish-purple color, and measuring between 0.5 and $3 \mathrm{~cm}$ in diameter [55, 57, 58, 69-73]. Livedo reticularis, racemose, or unspecified may also occur in $16.7-80.0 \%$ of cases, and ulcerations in $14.3-63.7 \%$ of cases [55, 57-59, 69-74].

Less frequent manifestations of the disease are purpura (0$32 \%)$ and atrophie blanche $(25.8-45.4 \%)[57-59,72]$. Severe cases of gangrene have also been reported $[69,70,75,76]$. Cutaneous arteritis-related lesions are most commonly found on the legs, in up to $97 \%$ of cases $[55,57,58,72]$.

Although being considered a vasculitis limited to the skin, cutaneous arteritis can also involve the nerves and muscles underlying the affected skin [55, 57]. Therefore, paresthesia (25-45.2\%), myalgia (22-75\%), and neuropathy (2-50\%) may occur $[55,57-59,69-72,74]$. Arthralgia (19.4-75\%) 
and constitutional symptoms such as fever, weight loss, and asthenia $(13.3-67.7 \%)$ have also been reported [57, 59, 69-72, 74].

\section{Diagnostic Evaluation}

The diagnosis of cutaneous arteritis is based on clinical manifestations, suggestive histology, and exclusion of systemic involvement.

In order to exclude other possible causes of vasculitis or systemic PAN, a thorough disease assessment, including the request of a complete blood count, CRP and ESR, renal and liver function tests, cryoglobulins, RF, ANCA, ANA, and complement levels, is often required [65]. However, in cutaneous arteritis, laboratory findings are often unspecific. Mild anemia, moderate leukocytosis, and increased acute phase reactants are frequently encountered [55, 69-73]. ANCA is usually negative, except for perinuclear ANCA in minocyclineinduced cutaneous arteritis [66].

Histologically, an incisional biopsy is preferred and should include adipose tissue. It can show neutrophilic muscular vessel vasculitis at arterial branch points, located either at the dermalsubcutis junction or within the subcutis (Fig. 3) [25, 77]. As vessel involvement is segmental and focal, repeated biopsies may be necessary $[9,25,77]$. Direct immunofluorescence may show vascular deposits, mainly C3 and IgM [60, 61].

In patients with symptoms suggesting systemic involvement, such as abdominal pain and renal dysfunction or hypertension, an imaging exam should be considered to exclude this hypothesis [72].

In 2008, Nakamura et al. [78] proposed draft diagnostic criteria for cutaneous arteritis consisting of the presence of cutaneous manifestations (subcutaneous nodules, livedo, purpura, and ulcers) and compatible histology showing fibrinoid necrotizing vasculitis of small- and medium-sized arteries, without disease manifestations suggestive of systemic involvement of PAN (fever, weight-loss, hypertension, renal or intestinal manifestations, cerebral vasculitis, heart disease, pleuritis, peripheral neuropathy or arthralgia/myalgia out of the skin lesion, and abnormal arteriography). However, as mentioned above, some patients may have mild constitutional symptoms and still be diagnosed with vasculitis limited to the skin. These criteria are yet to be validated and, therefore, should be used with caution in clinical practice.

\section{Treatment and Prognosis}

Treatment of cutaneous arteritis includes a wide range of options, highly dependent on disease manifestations and severity. Initial conservative measures on self-care should be instructed to all patients, such as prevention of cold exposure, leg rest and elevation, and avoidance of excessive standing or wearing tightfitting clothes [23].

Mild cases presenting with nodular skin lesions and livedo reticularis can be managed with topical glucocorticoids and oral NSAIDs [55, 69, 73, 74]. Dapsone can also be used [59, 79]. Occasionally, lower doses of oral glucocorticoids (< $20 \mathrm{mg} /$ day of prednisone or equivalent) may be necessary to induce remission $[55,59,69,71]$.

In relapsing or severe forms of the disease (e.g., presence of ulcers, necrosis, or neuropathy) and cases refractory to glucocorticoids, immunosuppressive agents should be considered, in addition to higher doses of glucocorticoids ( $>20 \mathrm{mg} /$ day of prednisone or equivalent, oral, or IV). In a recent retrospective study, which included 31 patients diagnosed with cutaneous arteritis, more than half the cases required immunosuppressive agents to control disease manifestations [57], being methotrexate the treatment of choice (51.6\%) [57]. Other drugs, such as azathioprine, sulfasalazine, and mycophenolate, have also shown efficacy in treating patients with this disease [59, $73,74,80 \cdot 81]$. Due to its safety profile, cyclophosphamide should only be reserved for very severe forms of the disease [72, 74, 80• 82].

Evidence on the use of biologic agents to treat cutaneous arteritis is scarce. Rituximab has been suggested as an appropriate alternative to cyclophosphamide, particularly in patients with severe cutaneous arteritis presenting with ulcers or necrosis [80 $]$. Anti-TNF treatment, namely infliximab and etanercept, has also been successfully employed in six cases of refractory pediatric cutaneous arteritis [79]. Nevertheless, prospective studies are warranted. Figure 4 shows a proposed algorithm for cutaneous arteritis treatment.

In specific cases of association with streptococcal infection, penicillin should be included in the treatment management.
Fig. 3 Cutaneous arteritis. (a) Affected artery in the upper subcutis showing marked fibrin extravasation into the wall (black arrow) $(\mathrm{H} \& \mathrm{E} \times 100)$. Inflammation is localized to the vessel and its immediate vicinity. (b) The fragmentation of the internal elastic lamina (arrow) is best appreciated by the use of a stain for elastic tissue (orcein $x$ 200)
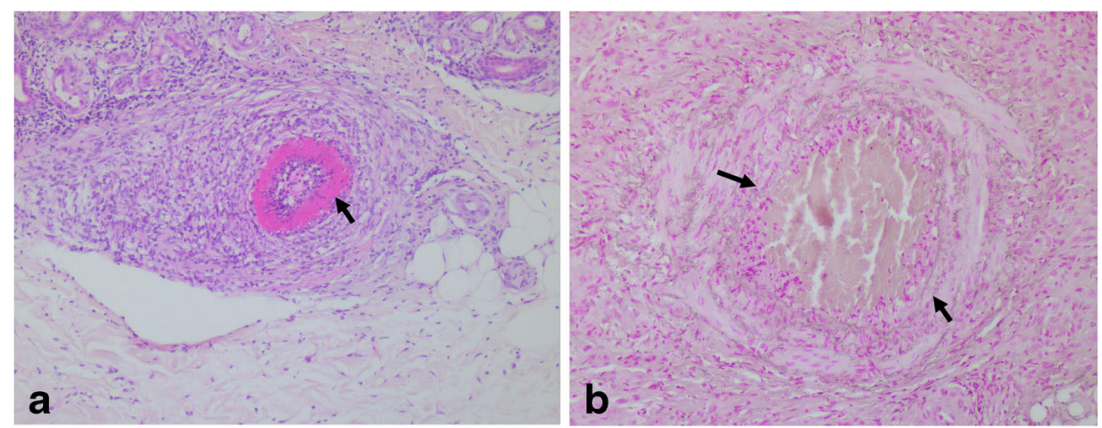
For patients whose relapses are associated with recurrent infections, long-term penicillin and tonsillectomy may be necessary [62, 64, 72].

The prognosis of cutaneous arteritis is usually favorable, without other organ complications; however, it can have a chronic and relapsing course [59]. Progression to systemic PAN is unusual and has only been described in up to 2.4$10 \%$ of cases $[59,69]$.

\section{Differences Between Cutaneous Arteritis and Systemic PAN}

While it is still debated if cutaneous arteritis should be considered a cutaneous form of PAN [55, 59, 73], the 2012 CHCC clearly separates these entities and does not consider cutaneous arteritis as a limited manifestation of systemic PAN [4].

Systemic PAN can present the same skin manifestations that cutaneous arteritis presents in up to $58 \%$ of patients [83]. Moreover, they both occur in patients with a mean age of approximately 50 years [84], share the same histologic findings $[25,83]$, and are not associated with the presence of ANCA [4].

Nevertheless, unlike cutaneous arteritis, systemic PAN affects more frequently the male sex, with a male:female proportion of $1.5: 1[59,80 \bullet, 84]$, and can present visceral involvement in any organ, except for the lungs [84], ultimately leading to tissue ischemia or hemorrhage due to arterial occlusion and/or rupture of the related inflamed arteries [83]. Therefore, systemic PAN is associated with worse outcomes and higher mortality rates than cutaneous arteritis [59, 85]. Although

Fig. 4 Proposed treatment algorithm for cutaneous arteritis.

(1) Severe disease: presence of

ulcers, necrosis, or neuropathy.

(2) Infliximab or etanercept

(evidence based on pediatric

cases) cutaneous arteritis follows a more benign disease course, it has also been reported to present higher rates of relapse than systemic PAN [59, 74, 80•].

\section{Primary Central Nervous System Vasculitis}

Primary CNS vasculitis, or primary angiitis of the CNS, is a rare and diffuse SOV affecting the brain and spinal cord. It is often a severe form of vasculitis, with a wide range of possible neurological symptoms and signs that frequently requires aggressive immunosuppressive therapy to control disease manifestations (e.g., high doses of glucocorticoids and cyclophosphamide) [86]. Further details on this disease have recently been reviewed in this journal [87].

\section{Isolated Aortitis}

Aortitis encompasses a group of non-infectious and infectious disorders leading to inflammation of the aorta [88•, 89-91]. Many systemic diseases may involve the aorta, namely giant cell arteritis (GCA), Takayasu's arteritis (TAK), other vasculitides (Behçet's disease, Cogan's syndrome, AAV, relapsing polychondritis), non-vasculitis rheumatic disorders (rheumatoid arthritis, ankylosing spondylitis, systemic lupus erythematosus), IgG4-related disease (IgG4-RD), and sarcoidosis. Infectious aortitis is far less common than non-infectious aortitis, particularly in developed countries, and may be caused by syphilis, mycobacterium tuberculosis, and

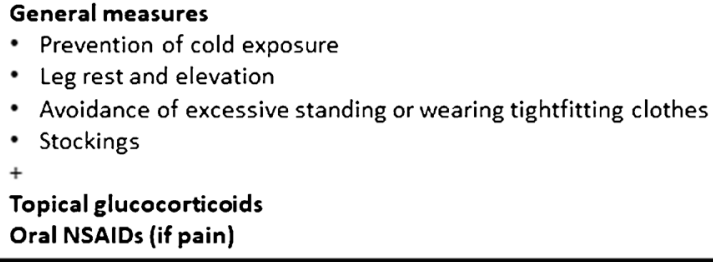

If refractory or relapsing:

Add oral prednisone (or equivalent) $<20 \mathbf{m g} /$ day (in tapering regimen) Consider adding dapsone

If refractory or relapsing:

Oral /IV prednisone (or equivalent) $>20 \mathrm{mg} /$ day (in tapering regimen)

Methotrexate; azathioprine; sulfasalazine or mycophenolate mofetil

If refractory:

Add cyclophosphamide; rituximab or anti-TNF ${ }^{2}$ 
bacterial, viral, or fungal infections [90, 92]. In some patients, aortitis may be identified without other accompanying features suggestive of systemic vasculitis, termed by the 2012 CHCC nomenclature as "isolated aortitis" [4]. In 2015, a consensus statement of the Society for Cardiovascular Pathology and the Association for European Cardiovascular Pathology endorsed the terminology "clinically isolated aortitis" to describe patients with histopathologic features of aortitis incidentally found after the examination of resected aortic segments [91]. Nevertheless, no specific histologic pattern is attributed to this proposed subgroup of patients. They may present a granulomatous inflammation, indistinguishable from cases of GCA or TAK, or less frequently a lymphoplasmacytic inflammation with the same features as patients with IgG4-RD [91].

Isolated aortitis may also be identified by vascular imaging (e.g., MRA, CTA, FDG-PET) [88•, 93, 94]. In comparison to the pathologically defined isolated aortitis, patients with imaging-defined isolated aortitis often have involvement of the aortic arch and descending thoracic aorta, but not so commonly of the ascending aorta (Fig. 5); frequently present an accompanying increase in CRP and ESR values; and may have an underlying infection as described above as the cause of aortitis [88•].

Currently, it is still unclear if isolated aortitis is a distinct disorder or, by contrast, a group of heterogeneous diseases with the same initial presentation. It is also not known if a patient presenting with isolated aortitis may, in fact, have a smoldering, subclinical inflammation in other locations that may take years to unravel. Therefore, managing patients with isolated aortitis poses a challenge. In a first approach, it is crucial to exclude infection given the obvious treatment implications [92]. Then, immunosuppressive therapy is frequently initiated. Most treatment regimens used in these patients are extrapolated from the evidence available for GCA and TAK.
Although still debatable, systemic glucocorticoids are the mainstay therapy for patients with isolated aortitis, particularly to prevent the occurrence of aortic aneurysms and dissections in the future [93, 95-98]. Other immunosuppressants, such as methotrexate, azathioprine, cyclophosphamide, and tocilizumab, have also been successfully applied [93]. In the cases of aortitis in the context of IgG4-RD, rituximab may also present as an effective alternative $[99,100]$.

\section{Other Single-Organ Vasculitides}

These include other less frequent forms of SOV that may have a unifocal or multifocal distribution. Unifocal variants of SOV have been reported to affect the breasts, testicles, gynecological and gastrointestinal organs, and the already mentioned aorta [1]. In general, the diagnosis of SOV at these sites is usually established incidentally after unrelated biopsy/surgical procedures [101-103]. It frequently follows a benign course, and progression to systemic vasculitis is uncommon. Surgical excision is often sufficient to attain cure; however, systemic glucocorticoids, with or without additional immunosuppression, are sometimes necessary to achieve remission [101-104].

SOV of the breasts usually manifests with one or more painful nodules that can be unilateral or bilateral [101]. Histology often reveals small- and medium-sized vessel inflammation, with or without vessel necrosis, which can be granulomatous or non-granulomatous [101]. Exclusion of systemic vasculitis [105] is crucial, given there have been reports of granulomatosis with polyangiitis (GPA), GCA, and PAN cases involving the mammary tissue $[101,105,106]$. Differential diagnosis with non-puerperal mastitis, sarcoidosis, fungal infections, tuberculosis, Mondor's disease, and malignancy should also be considered $[1,101,106]$.
Fig. 5 Computed tomography angiogram of a patient with isolated aortitis. Axial view (a) and sagittal view (b) showing concentric wall thickening of the aortic arch and descending thoracic aorta (green arrows)
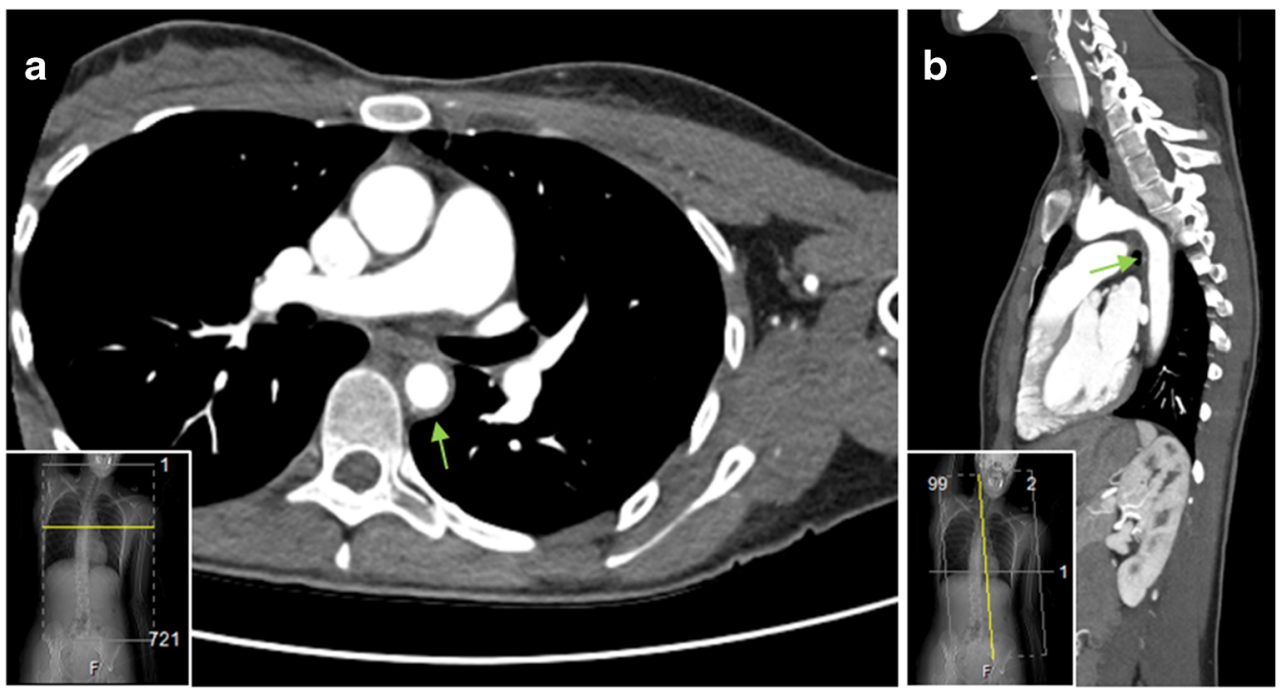
Gynecologic vasculitis commonly presents as an SOV rather than as a manifestation of a systemic vasculitis (e.g., GCA) [103, 107]. Gynecologic SOV often affects the cervix and manifests with vaginal bleeding, whereas systemic vasculitis with gynecologic involvement is more frequently associated with asymptomatic abdominal masses [103]. Histologically, both gynecologic SOV and systemic vasculitis with gynecologic manifestations can affect medium and small vessels; however, gynecologic SOV is more commonly associated with non-granulomatous changes and systemic vasculitis with granulomatous inflammation [103].

Testicular vasculitis usually presents with a unilateral painful testicular mass or enlarged testicle [102]. It is frequently interpreted initially as a malignant tumor, which should always be ruled out $[102,108]$. Biopsy findings commonly reveal the predominant involvement of medium-sized vessels with a non-granulomatous inflammation pattern [102, 108]. Concomitant systemic vasculitis must be sought, in particular systemic PAN [102, 108].

Vasculitis of abdominal territories occurs less frequently as an SOV than as part of a systemic vasculitis, in particular PAN [2, 109]. Nevertheless, gastrointestinal SOV has been reported in the appendix (most common location), esophagus, stomach, omentum, small and large intestine, gallbladder, and pancreas [2]. It often manifests with abdominal pain [59, 110]. Possible complications such as ulcers, bowel perforation, peritonitis, bleeding, and bowel ischemia contribute to a greater risk of severe morbidity, and mortality that can reach $40 \%$ [2, $59,109,110]$. Although progression to systemic vasculitis has been previously reported in up to $26 \%$ of cases [111], more recent studies do not confirm this observation [59, 110].

Diffuse or multifocal forms of SOV commonly represent severe variants of SOV that cannot be treated with surgical resection. Besides the already mentioned skin and CNS involvement, multifocal SOV may also affect peripheral nerves, kidneys, retina, calf muscles, and coronary and pulmonary vessels [2].

SOV restricted to the peripheral nervous system has been termed by the Peripheral Nerve Society as "non-systemic vasculitis neuropathy (NSVN)" [112], and it accounts for approximately $25 \%$ of all vasculitic neuropathies [113]. It is a necrotizing vasculitis, characterized by mononuclear infiltrates and immune deposits, and it predominantly affects the small- and medium-sized vessels of the epineurium/ perineurium of the distal nerves [2, 114, 115]. Patients may present with multifocal neuropathy, asymmetric polyneuropathy, and distal symmetric polyneuropathy, resulting in weakness and sensory loss [114]. Moreover, $15 \%$ of patients may have purely or predominantly sensory signs and symptoms, and $20 \%$ have no pain [114]. Constitutional symptoms may be present in $30 \%$ of patients [114]. Diagnosis is based on biopsy findings and exclusion of clinical manifestations suggestive of systemic vasculitis [112]. However, the sensitivity of sural nerve and superficial peroneal nerve/peroneus brevis muscle biopsies can be as low as $50-60 \%$ [112]. A patient can still be diagnosed with NSVN, despite the biopsy results, based on a typical clinical presentation (one or more acute attacks of painful, multifocal, or asymmetric involvement of sensory or sensory-motor nerves with lower limb predominance) and electromyographic or clinical evidence of the disease. [116]. All patients with progressive or active NSVN should be treated with immunosuppressants [112]. Systemic glucocorticoids, in combination with cyclophosphamide or methotrexate, for induction of disease remission, represent the best treatment strategy with fewer disease relapses and long-term sequelae when compared to glucocorticoids in monotherapy [114]. Rituximab may also be an effective alternative, as suggested by the AAV trials [117, 118]. Most patients respond well to treatment; however, disease relapses may occur in approximately $30 \%$ of treated patients $[114,119,120]$. Approximately $10 \%$ of NSVN patients will progress to systemic vasculitis [113].

Renal vasculitis may also occur without evidence of systemic involvement. Histologic features of patients with renal SOV may resemble or be indistinguishable from those seen in patients with AAV, PAN, or GCA [121-123]. In comparison to AAV, renal SOV is associated with better outcomes in terms of progression to end-stage renal disease and death [124]. Creatinine serum level at disease presentation has been recognized as the best predictor of poor renal outcomes in renal SOV [123].

Retinal vasculitis is a sight-threatening inflammatory condition that can rarely occur as an SOV. It is more commonly associated with other diagnoses, such as systemic vasculitis (e.g., Behçet's disease, AAV) or infections (e.g., tuberculosis, syphilis), which should always be sought [125]. Vasculitis restricted to the lower limbs, particularly the calves, has also been described [1, 2] and patients with this variant of SOV may present AAV-, PAN-, or GCA-type lesions [126-131]. Rare cases of eosinophilic coronary monoarteritis [132-134] and isolated pulmonary arteritis, also named isolated pulmonary Takayasu's arteritis [135-139], have also been reported in the literature and may be associated with life-threatening disease manifestations.

\section{Conclusion}

Localized vasculitides are a group of relatively rare conditions with a wide range of symptoms depending on the affected organ. Currently, the term SOV has been more widely used to better reflect the isolated nature of this subtype of vasculitis. Diagnosis is usually established based on biopsy findings and exclusion of systemic involvement, which can frequently be a challenge in clinical practice. Treatment of SOV can be as simple as the administration of topical agents but can also imply surgical excision and/or systemic immunosuppression. 
Nevertheless, there is still a lack of robust evidence to correctly delineate treatment strategies in these diseases. Prognosis of SOV is usually favorable and with better outcomes than in systemic vasculitis.

Acknowledgements The authors would like to thank Dr. Pedro Garrido, from the Dermatology Department of Hospital Santa Maria, CHULN, for providing the clinical image of leukocytoclastic angiitis (Fig. 1a).

\section{Declarations}

Conflict of Interest The authors declare no competing interests.

Human and Animal Rights and Informed Consent This article does not contain any studies with human or animal subjects performed by any of the authors.

\section{References}

Papers of particular interest, published recently, have been highlighted as:

\section{- Of importance}

1. Atisha-Fregoso Y, Hinojosa-Azaola A, Alcocer-Varela J. Localized, single-organ vasculitis: clinical presentation and management. Clin Rheumatol. 2013;32:1-6.

2. Hernández-Rodríguez J, Hoffman GS. Updating single-organ vasculitis. Curr Opin Rheumatol. 2012;24:38-45.

3. Hernández-Rodríguez J, Molloy ES, Hoffman GS. Single-organ vasculitis. Curr Opin Rheumatol. 2008;20:40-6.

4. Jennette JC, Falk RJ, Bacon PA, Basu N, Cid MC, Ferrario F, et al. 2012 Revised International Chapel Hill Consensus Conference Nomenclature of Vasculitides. Arthritis Rheum. 2013;65:1-11.

5. Bolognia JL, editor. Dermatology: ExpertConsult. 3rd ed ff. Edinburgh: Elsevier; 2012.

6. Ellis A, Billings SD, Khanna U, Warren CB, Piliang M, Vij A, et al. Diagnoses of hospitalized patients with skin abnormalities prompting biopsy by consulting dermatologists: a 3-year review from a tertiary care center. J Cutan Pathol. 2020;47:346-56.

7. Arora A, Wetter DA, Gonzalez-Santiago TM, Davis MDP, Lohse CM. Incidence of leukocytoclastic vasculitis, 1996 to 2010: a population-based study in Olmsted County, Minnesota. Mayo Clin Proc. 2014;89:1515-24.

8. Carlson JA, Ng BT, Chen K-R. Cutaneous vasculitis update: diagnostic criteria, classification, epidemiology, etiology, pathogenesis, evaluation and prognosis. Am J Dermatopathol. 2005;27: 504-28.

9. Chen K-R, Carlson JA. Clinical approach to cutaneous vasculitis. Am J Clin Dermatol. 2008;9:71-92.

10. Jameson JL, editor. Harrison's principles of internal medicine. Twentieth ed. New York: McGraw-Hill Education; 2018.

11. Mayor-Ibarguren A, Feito-Rodriguez M, Quintana Castanedo L, Ruiz-Bravo E, Montero Vega D, Herranz-Pinto P. Cutaneous small vessel vasculitis secondary to COVID-19 infection: a case report. J Eur Acad Dermatol Venereol. 2020 [cited 2020 Nov 7];34. Available from: https://doi.org/10.1111/jdv.16670.

12. Dominguez-Santas M, Diaz-Guimaraens B, Garcia Abellas P, Moreno-Garcia del Real C, Burgos-Blasco P, Suarez-Valle A.
Cutaneous small-vessel vasculitis associated with novel 2019 coronavirus SARS-CoV-2 infection (COVID-19). J Eur Acad Dermatol Venereol. 2020 [cited 2020 Nov 7];34. Available from: https://doi.org/10.1111/jdv.16663.

13. Pastuszczak M, Celińska-Löwenhoff M, Sułowicz J, Wojas-Pelc A, Musiał J. Clinical study on single-organ cutaneous small vessels vasculitis (SoCSVV). Medicine. 2017;96:e6376. This study focuses on characterizing single-organ cutaneous small-vessel vasculitis and identify its precipitating factors and risk of recurrence.

14. Tai YJ, Chong AH, Williams RA, Cumming S, Kelly RI. Retrospective analysis of adult patients with cutaneous leukocytoclastic vasculitis. Australas J Dermatol. 2006;47:92-6.

15. Loricera J, Blanco R, Ortiz-Sanjuan F, Hernandez JL, Pina T, Gonzalez-Vela MC, et al. Single-organ cutaneous small-vessel vasculitis according to the 2012 revised International Chapel Hill Consensus Conference Nomenclature of Vasculitides: a study of 60 patients from a series of 766 cutaneous vasculitis cases. Rheumatology. 2015;54:77-82.

16. Martinez-Taboada MDVM, Blanco MDR, Garcia-Fuentes MDM, Rodriguez-Valverde MDV. Clinical features and outcome of 95 patients with hypersensitivity vasculitis. Am J Med. 1997;102: 186-91.

17. Russell JP, Gibson LE. Primary cutaneous small vessel vasculitis: approach to diagnosis and treatment. Int J Dermatol. 2006;45:313.

18. Baigrie D, Bansal P, Goyal A, Crane JS. Leukocytoclastic vasculitis. StatPearls. Treasure Island: StatPearls Publishing; 2020 [cited 2020 Nov 1]. Available from: http://www.ncbi.nlm.nih.gov/ books/NBK482159/.

19. Micheletti RG. Cutaneous vasculitis in rheumatologic disease: Current concepts of skin and systemic manifestations. Clin Dermatol. 2018;36:561-6.

20. Wick MR, Patterson JW. Cutaneous paraneoplastic syndromes. Semin Diagn Pathol. 2019;36:211-28.

21. Leavitt RY, Fauci AS. Polyangiitis overlap syndrome. Am J Med. 1986;81:79-85.

22. Weng C-H, Liu Z-C. Drug-induced anti-neutrophil cytoplasmic antibody-associated vasculitis. Chin Med J. 2019;132:2848-55.

23. Carlson JA, Cavaliere LF, Grant-Kels JM. Cutaneous vasculitis: diagnosis and management. Clin Dermatol. 2006;24:414-29.

24. Chango Azanza JJ, Calle Sarmiento PM, Lopetegui Lia N, Alexander SA, Modi V. Leukocytoclastic vasculitis: an early skin biopsy makes a difference. Cureus. 2020 May 1;12(5):e7912. https://doi.org/10.7759/cureus. 7912 .

25. Carlson JA. The histological assessment of cutaneous vasculitis. Histopathology. 2010;56:3-23.

26. Kang Y, Park J, Ha Y-J, Kang M, Park H-J, Lee S-W, et al. Differences in clinical manifestations and outcomes between adult and child patients with Henoch-Schönlein purpura. J Korean Med Sci. 2014;29:198-203.

27. Chhabra S, Singh S, Radotra B, Kumar B, Minz R. Direct immunofluorescence of skin biopsy: perspective of an immunopathologist. Indian J Dermatol Venereol Leprol. 2010;76:150.

28. Micheletti RG, Pagnoux C. Management of cutaneous vasculitis. Presse Med. 2020;49:104033.

29. Sais G, Vidaller A, Jucglà A, Servitje O, Condom E, Peyrí J. Prognostic factors in leukocytoclastic vasculitis: a clinicopathologic study of 160 patients. Arch Dermatol. 1998;134:309-15.

30. Callen JP, af Ekenstam E. Cutaneous leukocytoclastic vasculitis: clinical experience in 44 patients. South Med J. 1987;80:848-51.

31. Sais G, Vidaller A, Jucglà A, Gallardo F, Peyrí J. Colchicine in the treatment of cutaneous leukocytoclastic vasculitis. Results of a prospective, randomized controlled trial. Arch Dermatol. 1995;131:1399-402. 
32. Cribier B, Cuny JF, Schubert B, Colson A, Truchetet F, Crosshans E. Recurrent annular erythema with purpura: a new variant of leucocytoclastic vasculitis responsive to dapsone. Br J Dermatol. 1996;135:972-5.

33. Ruiz Villaverde R, Blasco Melguizo J, Martin Sanchez M, Naranjo SR. Annular leucocytoclastic vasculitis: response to dapsone. J Eur Acad Dermatol Venerol. 2002;16:544-6.

34. Seybold H, Simon M, Schuler G, Lüftl M. Therapierefraktäre kutane nekrotisierende Vaskulitis: Erfolgreiche Sulfontherapie. Hautarzt. 2006;57:47-50.

35. Callen JP. Azathioprine. An effective, corticosteroid-sparing therapy for patients with recalcitrant cutaneous lupus erythematosus or with recalcitrant cutaneous leukocytoclastic vasculitis. Arch Dermatol. 1991;127:515-22.

36. Espinoza LR, Espinoza CG, Vasey FB, Germain BF. Oral methotrexate therapy for chronic rheumatoid arthritis ulcerations. J Am Acad Dermatol. 1986;15:508-12.

37. Upchurch KS, Heller K, Bress NM. Low-dose methotrexate therapy for cutaneous vasculitis of rheumatoid arthritis. J Am Acad Dermatol. 1987;17:355-9.

38. Williams HC, Pembroke AC. Methotrexate in the treatment of vasculitic cutaneous ulceration in rheumatoid arthritis. J R Soc Med. 1989;82:763.

39. Lopez L, Davis K, Kohler P, Schocket A. The hypocomplementemic urticarial-vasculitis syndrome: therapeutic response to hydroxychloroquine. J Allergy Clin Immunol. 1984;73:600-3.

40. Melamed J, Laznickova H. Combination therapy with dapsone, colchicine and hydroxychloroquine in the treatment of urticarial vasculitis. J Allergy Clin Immunol. Elsevier. 2007;119:S204.

41. Haeberle MT, Adams WB, Callen JP. Treatment of severe cutaneous small-vessel vasculitis with mycophenolate mofetil. Arch Dermatol. 2012;148:887-8.

42. Worm M, Sterry W, Kolde G. Mycophenolate mofetil is effective for maintenance therapy of hypocomplementaemic urticarial vasculitis. Br J Dermatol. 2000;143:1324.

43. Nikibakhsh AA, Mahmoodzadeh H, Karamyyar M, Hejazi S, Noroozi M, Macooie AA, et al. Treatment of complicated Henoch-Schönlein purpura with mycophenolate mofetil: a retrospective case series report. Int J Rheumatol. 2010;2010:1-5.

44. Swaminath A, Magro CM, Dwyer E. Refractory urticarial vasculitis as a complication of ulcerative colitis successfully treated with rituximab. J Clin Rheumatol. 2011;17:281-3.

45. El-Reshaid K, Madda JP. Rituximab Therapy for severe cutaneous leukocytoclastic angiitis refractory to corticosteroids, Cellcept and cyclophosphamide. Case Rep Dermatol. 2013;5:115-9.

46. Liu PY, Prete PE, Kukes G. Leukocytoclastic Vasculitis in a patient with type 1 cryoglobulinemia. Case Rep Rheumatol. 2011;2011:1-3.

47. Mang R, Ruzicka T, Stege H. Therapy for severe necrotizing vasculitis with infliximab. J Am Acad Dermatol. 2004;51:321-2.

48. Ong CS, Benson EM. Successful treatment of chronic leucocytoclastic vasculitis and persistent ulceration with intravenous immunoglobulin. Br J Dermatol. 2000;143:447-9.

49. Stratigos J, Katsambas A, Potouridou E. Cyclosporin: a therapy for allergic cutaneous vasculitis with multiple recurrences. J Dermatol Treat. 1994;5:93-5.

50. Tosca AD, Ioannidou DJ, Katsantonis JC, Kyriakis KP. Cyclosporin A in the treatment of cutaneous vasculitis. Clinical and cellular effects. J Eur Acad Dermatol Venerol. 1996;6:13541.

51. Bezerra AS, Polimanti AC, de Oliveira RA, Fürst RV d C, Criado PR, Corrêa JA. Diagnóstico e terapêutica precoce de vasculite leucocitoclástica: relato de caso. J Vasc Bras. 2020;19:e20180072.

52. Lindberg K. Ein Beitrag zur Kenntnis der Periarteriitis nodosa. Acta Med Scand. 1931;76:183-225.
53. Herbert CR, Russo GG. Polyarteritis nodosa and cutaneous polyarteritis nodosa. Skinmed. 2003 Sep-Oct;2(5):277-83; quiz 284-5. https://doi.org/10.1111/j.1540-9740.2003.02214.x.

54. Chasset F, Francès C. Cutaneous manifestations of medium- and large-vessel vasculitis. Clin Rev Allergy Immunol. 2017;53:452 68.

55. Daoud M, Hutton K, Gibson L. Cutaneous periarteritis nodosa: a clinicopathological study of 79 cases. Br J Dermatol. 1997;136: 706-13.

56. Bansal N-K, Houghton KM. Cutaneous polyarteritis nodosa in childhood: a case report and review of the literature. Arthritis. 2010;2010:1-7.

57. Munera-Campos M, Bielsa I, Martínez-Morillo M, Aparicio G, Olivé A, Ferrándiz C. Manifestations, clinical course and prognostic markers in cutaneous polyarteritis nodosa. J Dtsch Dermatol Ges. 2020 Nov;18(11):1250-9. https://doi.org/10.1111/ddg. 14271.

58. Criado PR, Marques GF, Morita TCAB, de Carvalho JF. Epidemiological, clinical and laboratory profiles of cutaneous polyarteritis nodosa patients: report of 22 cases and literature review. Autoimmun Rev. 2016;15:558-63.

59. Alibaz-Oner F, Koster MJ, Crowson CS, Makol A, Ytterberg SR, Salvarani C, et al. Clinical spectrum of medium-sized vessel vasculitis: medium-sized vessel vasculitis. Arthritis Care Res. 2017;69:884-91.

60. Diaz-Perez JL, Schroeter AL, Winkelmann RK. Cutaneous periarteritis nodosa: immunofluorescence studies. Arch Dermatol. 1980 Jan;116(1):56-8.

61. Kawakami T, Yamazaki M, Mizoguchi M, Soma Y. High titer of anti-phosphatidylserine-prothrombin complex antibodies in patients with cutaneous polyarteritis nodosa. Arthritis Rheum. 2007;57:1507-13.

62. Till SH, Amos RS. Long-term follow-up of juvenile-onset cutaneous polyarteritis nodosa associated with streptococcal infection. Rheumatology. 1997;36:909-11.

63. Inoue N, Shimizu M, Mizuta M, Ikawa Y, Yachie A. Refractory cutaneous polyarteritis nodosa: successful treatment with etanercept. Pediatr Int. 2017;59:751-2.

64. Breda L, Franchini S, Marzetti V, Chiarelli F. Intravenous immunoglobulins for cutaneous polyarteritis nodosa resistant to conventional treatment. Scand J Rheumatol. 2016;45:169-70.

65. Morgan AJ, Schwartz RA. Cutaneous polyarteritis nodosa: a comprehensive review: cutaneous polyarteritis nodosa. Int J Dermatol. 2010;49:750-6.

66. Culver B, Itkin A, Pischel K. Case report and review of minocycline-induced cutaneous polyarteritis nodosa. Arthritis Rheum. 2005;53:468-70.

67. Navon Elkan P, Pierce SB, Segel R, Walsh T, Barash J, Padeh S, et al. Mutant adenosine deaminase 2 in a polyarteritis nodosa vasculopathy. N Engl J Med. 2014;370:921-31.

68. Gonzalez Santiago TM, Zavialov A, Saarela J, Seppanen M, Reed AM, Abraham RS, et al. Dermatologic features of ADA2 deficiency in cutaneous polyarteritis nodosa. JAMA Dermatol. 2015;151: $1230-4$.

69. Chen K-R. Cutaneous Polyarteritis nodosa: a clinical and histopathological study of 20 cases. J Dermatol. 1989;16:429-42.

70. Borrie P. Cutaneous polyarteritis nodosa. Br J Dermatol. 1972;87: 87-95.

71. Moreland LW, Ball GV. Cutaneous polyarteritis nodosa. Am J Med. 1990 Apr;88(4):426-30. https://doi.org/10.1016/00029343(90)90502-5.

72. Bauza A, Espana A, Idoate M. Cutaneous polyarteritis nodosa. Br J Dermatol. 2002;146:694-9.

73. Rogalski C, Sticherling M. Panarteritis cutanea benigna ? An entity limited to the skin or cutaneous presentation of a systemic 
necrotizing vasculitis? Report of seven cases and review of the literature. Int J Dermatol. 2007;46:817-21.

74. Kint N, De Haes P, Blockmans D. Comparison between classical polyarteritis nodosa and single organ vasculitis of medium-sized vessels: a retrospective study of 25 patients and review of the literature. Acta Clin Belg. 2016;71:26-31.

75. Choi SW, Lew S, Cho SD, Cha HJ, Eum E-A, Jung HC, et al. Cutaneous polyarteritis nodosa presented with digital gangrene: a case report. J Korean Med Sci. 2006;21:371.

76. Stussi G, Schneider E, Trüeb RM, Seebach JD. Acral necrosis of the fingers as initial manifestation of cutaneous polyarteritis nodosa-a case report. Angiology. 2001 Jan;52(1):63-7. https:// doi.org/10.1177/000331970105200109.

77. Morimoto A, Chen K-R. Reappraisal of histopathology of cutaneous polyarteritis nodosa: reappraisal of histopathology of C-PAN. J Cutan Pathol. 2016;43:1131-8.

78. Nakamura T, Kanazawa N, Ikeda T, Yamamoto Y, Nakabayashi $\mathrm{K}$, Ozaki S, et al. Cutaneous polyarteritis nodosa: revisiting its definition and diagnostic criteria. Arch Dermatol Res. 2009;301: $117-21$.

79. Do N, Ringold S, Brandling-Bennett $\mathrm{H}$. Cutaneous polyarteritis nodosa in pediatric patients successfully treated with TNF- $\alpha$ inhibitor and methotrexate: case series and literature review. Pediatr Dermatol. 2019;36:932-5.

80. Shirai T, Shirota Y, Fujii H, Ishii T, Harigae H. Four distinct clinical phenotypes of vasculitis affecting medium-sized arteries. Scand J Rheumatol. 2019;48:308-14. This is a retrospective study that divides CPAN patients into four categories according to disease severity and compares clinical manifestations, treatment and outcomes.

81. Schartz NEC, Alaoui S, Vignon-Pennamen MD, Cordoliani F, Fermand JP, Morel P, et al. Successful treatment in two cases of steroid-dependent cutaneous polyarteritis nodosa with low-dose methotrexate. Dermatology. 2001;203:336-8.

82. Subbanna PK, Swaminathan R, Singh N. Cutaneous polyarteritis nodosa: a rare isolated cutaneous vasculitis. Indian Dermatol Online J. 2012;3:21-4.

83. Hernández-Rodríguez J, Alba MA, Prieto-González S, Cid MC. Diagnosis and classification of polyarteritis nodosa. J Autoimmun. 2014;48-49:84-9.

84. De Virgilio A, Greco A, Magliulo G, Gallo A, Ruoppolo G, Conte $\mathrm{M}$, et al. Polyarteritis nodosa: a contemporary overview. Autoimmun Rev. 2016;15:564-70.

85. Pagnoux C, Seror R, Henegar C, Mahr A, Cohen P, Le Guern V, et al. Clinical features and outcomes in 348 patients with polyarteritis nodosa: a systematic retrospective study of patients diagnosed between 1963 and 2005 and entered into the French vasculitis study group database. Arthritis Rheum. 2010;62:61626.

86. Dutra LA, de Souza AWS, Grinberg-Dias G, Barsottini OGP, Appenzeller S. Central nervous system vasculitis in adults: an update. Autoimmun Rev. 2017;16:123-31.

87. Byram K, Hajj-Ali RA, Calabrese L. CNS vasculitis: an approach to differential diagnosis and management. Curr Rheumatol Rep. 2018;20:37.

88. Cinar I, Wang H, Stone JR. Clinically isolated aortitis: pitfalls, progress, and possibilities. Cardiovasc Pathol. 2017;29:23-32. The authors give a detailed and updated overview on the epidemiology, pathology, etiology, management, and long-term outcomes of patients with clinically isolated aortitis.

89. Aghayev A, Bay CP, Tedeschi S, et al. Clinically isolated aortitis: imaging features and clinical outcomes: comparison with giant cell arteritis and giant cell aortitis. The International Journal of Cardiovascular Imaging. 2021 Apr;37(4):1433-43. https://doi. org/10.1007/s10554-020-02087-x.
90. Gornik HL, Creager MA. Aortitis. Circulation. 2008;117:303951.

91. Stone JR, Bruneval P, Angelini A, Bartoloni G, Basso C, Batoroeva L, et al. Consensus statement on surgical pathology of the aorta from the Society for Cardiovascular Pathology and the Association for European Cardiovascular Pathology: I. Inflammatory diseases. Cardiovasc Pathol. 2015;24:267-78.

92. Marvisi C, Accorsi Buttini E, Vaglio A. Aortitis and periaortitis: the puzzling spectrum of inflammatory aortic diseases. Presse Med. 2020;49:104018.

93. Espitia O, Samson M, Le Gallou T, Connault J, Landron C, Lavigne C, et al. Comparison of idiopathic (isolated) aortitis and giant cell arteritis-related aortitis. A French retrospective multicenter study of 117 patients. Autoimmun Rev. 2016;15:571-6.

94. Loricera J, Blanco R, Hernández JL, Carril JM, MartínezRodríguez I, Canga A, et al. Non-infectious aortitis: a report of 32 cases from a single tertiary centre in a 4-year period and literature review. Clin Exp Rheumatol. 2015;33:S-19-31.

95. Miller DV, Isotalo PA, Weyand CM, Edwards WD, Aubry M-C, Tazelaar HD. Surgical pathology of noninfectious ascending aortitis: a study of 45 cases with emphasis on an isolated variant. Am J Surg Pathol. 2006;30:9.

96. Wang H, Smith RN, Spooner AE, Isselbacher EM, Cambria RP, MacGillivray TE, et al. Giant cell aortitis of the ascending aorta without signs or symptoms of systemic vasculitis is associated with elevated risk of distal aortic events. Arthritis Rheum. 2012;64:317-9.

97. Svensson LG, Arafat A, Roselli EE, Idrees J, Clifford A, Tan C, et al. Inflammatory disease of the aorta: patterns and classification of giant cell aortitis, Takayasu arteritis, and nonsyndromic aortitis. J Thorac Cardiovasc Surg. 2015;149:S170-5.

98. Ferfar Y, Morinet S, Espitia O, Agard C, Vautier M, Comarmond $\mathrm{C}$, et al. Long-term outcome and prognosis factors of isolated aortitis. Circulation. 2020;142:92-4.

99. Maritati F, Corradi D, Versari A, Casali M, Urban ML, Buzio C, et al. Rituximab therapy for chronic periaortitis. Ann Rheum Dis. 2012;71:1262-4.

100. Carruthers MN, Topazian MD, Khosroshahi A, Witzig TE, Wallace ZS, Hart PA, et al. Rituximab for IgG4-related disease: a prospective, open-label trial. Ann Rheum Dis. 2015;74:1171-7.

101. Hernández-Rodríguez J, Tan CD, Molloy ES, Khasnis A, Rodríguez ER, Hoffman GS. Vasculitis involving the breast: a clinical and histopathologic analysis of 34 patients. Medicine. 2008;87:61-9.

102. Hernández-Rodríguez J, Tan CD, Koening CL, Khasnis A, Rodríguez ER, Hoffman GS. Testicular Vasculitis: findings differentiating isolated disease from systemic disease in 72 patients. Medicine. 2012;91:75-85.

103. Hernández-Rodríguez J, Tan CD, Rodríguez ER, Hoffman GS. Gynecologic vasculitis: an analysis of 163 patients. Medicine (Baltimore). 2009 May;88(3):169-81. https://doi.org/10.1097/ MD.0b013e3181a577f3.

104. Bastone P, Squifflet JL, Marbaix E, Houssiau F. Successful treatment of gynaecological involvement of granulomatosis with polyangiitis (Wegener's granulomatosis) by rituximab. Clin Exp Rheumatol. 2015 Mar-Apr;33(2 Suppl 89):S-142-4.

105. Tabbarah A, Voltaggio L. Giant cell arteritis of the breast. Arch Pathol Lab Med. 2017;141:1283-7.

106. Ren J, Liu J, Su J, Zhang J, Zhao J. Systemic vasculitis involving the breast: a case report and literature review. Rheumatol Int. 2019;39:1447-55.

107. Roma AA, Amador-Ortiz C, Liapis H. Significance of isolated vasculitis in the gynecological tract: what clinicians do with the pathologic diagnosis of vasculitis? Ann Diagn Pathol. 2014;18: 199-202. 
108. Brimo F, Lachapelle J, Epstein JI. Testicular Vasculitis: a series of 19 cases. Urology. 2011;77:1043-8.

109. Pagnoux C, Mahr A, Cohen P, Guillevin L. Presentation and outcome of gastrointestinal involvement in systemic necrotizing vasculitides: analysis of 62 patients with polyarteritis nodosa, microscopic polyangiitis, Wegener granulomatosis, Churg-Strauss syndrome, or rheumatoid arthritis-associated vasculitis. Medicine. 2005;84:115-28.

110. Salvarani C, Calamia KT, Crowson CS, Miller DV, Broadwell AW, Hunder GG, et al. Localized vasculitis of the gastrointestinal tract: a case series. Rheumatology. 2010;49:1326-35.

111. Burke AP, Sobin LH, Virmani R. Localized vasculitis of the gastrointestinal tract. Am J Surg Pathol. 1995;19:338-49.

112. Collins MP, Dyck PJB, Gronseth GS, Guillevin L, Hadden RDM, Heuss D, et al. Peripheral Nerve Society Guideline* on the classification, diagnosis, investigation, and immunosuppressive therapy of non-systemic vasculitic neuropathy: executive summary. $\mathrm{J}$ Peripher Nerv Syst. 2010;15:176-84.

113. Graf J, Imboden J. Vasculitis and peripheral neuropathy. Curr Opin Rheumatol. 2019;31:40-5.

114. Collins MP, Hadden RD. The nonsystemic vasculitic neuropathies. Nat Rev Neurol. 2017;13:302-16.

115. Collins MP, Arnold WD, Kissel JT. The neuropathies of vasculitis. Neurol Clin. 2013;31:557-95.

116. Hadden RDM, Collins MP, Živković SA, Hsieh S-T, Bonetto C, Felicetti P, et al. Vasculitic peripheral neuropathy: case definition and guidelines for collection, analysis, and presentation of immunisation safety data. Vaccine. 2017;35:1567-78.

117. Jones RB, Tervaert JWC, Hauser T, Luqmani R, Morgan MD, Peh $\mathrm{CA}$, et al. Rituximab versus cyclophosphamide in ANCAassociated renal vasculitis. N Engl J Med. 2010;363:211-20.

118. Stone JH, Merkel PA, Spiera R, Seo P, Langford CA, Hoffman GS, et al. Rituximab versus cyclophosphamide for ANCAassociated vasculitis. New Engl J Med. Massachusetts Medical Society. 2010;363:221-32.

119. Üçeyler N, Geng A, Reiners K, Toyka KV, Sommer C. Nonsystemic vasculitic neuropathy: single-center follow-up of $60 \mathrm{pa}-$ tients. J Neurol. 2015;262:2092-100.

120. Collins MP, Periquet MI, Mendell JR, Sahenk Z, Nagaraja HN, Kissel JT. Nonsystemic vasculitic neuropathy: insights from a clinical cohort. Neurology. 2003;61:623-30.

121. Pourafshar N, Sobel E, Segal M. A case of isolated renal involvement of polyarteritis nodosa successfully treated with steroid monotherapy. BMJ Case Rep. 2016. https://doi.org/10.1136/bcr2016-215702.

122. Watanabe R, Nakaya I, Kudo H, Yahata M, Sakuma T, Soma J. Isolated granulomatous renal arteritis: a variant form of giant cell arteritis with few macrophages. Intern Med. 2010;49(2):191-4. https://doi.org/10.2169/internalmedicine.49.2480.

123. Gigante A, Salviani C, Giannakakis K, Rosato E, Barbano B, Moroso A, et al. Clinical and histological outcome predictors in renal limited pauci-immune crescentic glomerulonephritis: a single centre experience. Int J Immunopathol Pharmacol. 2012 JanMar;25(1):287-92. https://doi.org/10.1177/039463201202500133.
124. Weidner S, Geuss S, Hafezi-Rachti S, Wonka A, Rupprecht HD. ANCA-associated vasculitis with renal involvement: an outcome analysis. Nephrol Dial Transplant. 2004;19:1403-11.

125. El-Asrar AMA, Herbort CP, Tabbara KF. A clinical approach to the diagnosis of retinal vasculitis. Int Ophthalmol. 2010;30:149 73.

126. Khellaf M, Hamidou M, Pagnoux C, Michel M, Brisseau JM, Chevallier X, et al. Vasculitis restricted to the lower limbs: a clinical and histopathological study. Ann Rheum Dis. 2007;66:554-6.

127. Parsa P, Rios A, Anderson LN, Eidt JF, Gable D, Grimsley B. Isolated lower extremity vasculitis leading to progressive critical limb ischemia. J Vasc Surg Cases Innov Tech. 2017;3:119-22.

128. Ojima Y, Sawada K, Fujii H, Shirai T, Saito A, Kagaya S, et al. Anti-neutrophil cytoplasmic antibody-associated vasculitis (AAV) restricted to the limbs. Intern Med. 2018;57:1301-8.

129. Kamimura T, Hatakeyama M, Torigoe K, Nara H, Kaneko N, Satou $\mathrm{H}$, et al. Muscular polyarteritis nodosa as a cause of fever of undetermined origin: a case report and review of the literature. Rheumatol Int. 2005;25:394-7.

130. Balbir-Gurman A, Nahir AM, Braun-Moscovici Y. Intravenous immunoglobulins in polyarteritis nodosa restricted to the limbs: case reports and review of the literature. Clin Exp Rheumatol. 2007;25:S28-30.

131. García F, Pedrol E, Casademont J, Mellado B, Córdoba R, Cid M, et al. Polyarteritis nodosa confined to calf muscles. J Rheumatol. 1992;19:303-5.

132. Carreon CK, Esposito MJ. Eosinophilic coronary monoarteritis. Arch Pathol Lab Med. 2014;138:979-81.

133. Arena V, Valerio L, Arena E, De-Giorgio F, Stigliano E, Monego $\mathrm{G}$, et al. Isolated eosinophilic coronary arteritis. J Clin Pathol. 2010;63:469-71.

134. Stoukas V, Dragovic LJ. Sudden deaths from eosinophilic coronary monoarteritis: a subset of spontaneous coronary artery dissection. Am J Forensic Med Pathol. 2009;30:268-9.

135. Fujita K, Kasama S, Kurabayashi M. Pitfalls in the management of isolated pulmonary Takayasu's arteritis after surgery: a case report of an experience during 34 months after a pulmonary artery graft replacement. J Cardiothorac Surg. 2016;11:7.

136. Yamazaki I, Ichikawa Y, Ishii M, Hamada T, Kajiwara H. Surgical case of isolated pulmonary Takayasu's arteritis. Circ J. 2005;69:500-2.

137. Alizadehasl A, Saedi S, Ganji H, Pourafkari L. Isolated peripheral pulmonary stenosis in Takayasu arteritis. Int J Rheum Dis. 2020;23:116-9.

138. Zhang Y-H, Song W-M, Wu M, Zhu J. Initial isolated Takayasu's arteritis of bilateral pulmonary artery branches. Rev Bras Reumatol Engl Ed. 2017;57:626-9.

139. Fukuda Y, Shirai K, Takamiya Y, Nathan M, Mito T, Yamagi D, et al. Isolated pulmonary arterial stenosis caused by Takayasu's arteritis in an elderly male. J Cardiol. 2008;51:196-200.

Publisher's Note Springer Nature remains neutral with regard to jurisdictional claims in published maps and institutional affiliations. 